\title{
O método científico na visão de graduandos em ciências biológicas - licenciatura da Universidade Federal de Sergipe/Campus São Cristóvão
}

\author{
The scientific method on the vision of licentiate graduate students in biological science \\ at the Universidade Federal de Sergipe/ Campus São Cristóvão \\ L. J. Carvalho; I. Almeida; C. R. P. Guimarães \\ Departamento de Biologia/ Laboratório de Bentos Costeiro/ Universidade Federal de Sergipe, 49100-000, \\ São Cristóvão-SE, Brasil
}

(laisdejesuscarvalho@hotmail.com)

(Recebido em 18 de outubro de 2016; aceito em 05 de junho de 2016)

\begin{abstract}
O ensino de ciências normalmente apresenta um amplo direcionamento à exploração do produto final das atividades e não o processo de construção do conhecimento científico. Dessa forma, nota-se a importância de conhecer quais concepções de método científico graduandos em Ciências Biológicas da Universidade Federal de Sergipe possuem, já que tais concepções podem interferir na sua forma de aprendizagem. Foram aplicados 88 questionários a fim de conhecer essas concepções. Observou-se que os graduandos, em sua maior parte, veem o método científico como um conjunto de normas ou um sistema de pesquisas padronizado em que há sempre a observação de um fato para elaboração de uma teoria. Dessa forma, fazse necessária uma maior discussão sobre como o conhecimento científico é produzido e sua importância para a sociedade.

Palavras Chaves: Ensino de Ciências; Ciência; Método Científico
\end{abstract}

The science education normally presents an extensive direction to exploitation of the final product of the activities and not the science knowledge building process. Thus, it is noticed the importance of knowing wich are the scientific method conceptions for graduate students in Biological Sciences at the Universidade Federal de Sergipe, since such conceptions may interfere in their way of schooling. 88 questionnaires were applied for know these conceptions. It was observed that the graduate students, mostly, see the scientific method as a set of rules or a standardized research system in which there is always the observation of a fact for the development of a theory. Therefore, it is necessary a further discussion on how the scientific knowledge is produced and its importance to society.

Keywords: Science Education; science; Scientific Method

\section{INTRODUÇÃO}

A ideia de ciência nos remete, muitas vezes, a uma visão estereotipada, associada ao trabalho de frios cientistas de jaleco branco, isolados em laboratórios renomados, nos quais, por meio de atitudes neutras desenvolvem pesquisas que podem mudar o destino da humanidade.

Esse problema é recorrente também ao ambiente escolar. O ensino de ciências entre os anos de 1980 e 1990 era centrado exclusivamente na transmissão de conhecimentos científicos, em que os professores eram sujeitos que faziam com que os alunos (vistos como passivos), adquirissem esses conhecimentos [1]. Dessa forma, não havia discussão sobre o real papel da ciência e sua construção ao longo da história. Hoje, os currículos de ensino de ciências buscam incluir componentes que estejam orientados na busca de aspectos sociais e pessoais dos estudantes [1]. Além disso, busca-se tirar o foco somente no ensino de conceitos e métodos, para incluir natureza das ciências e suas implicações mútuas com a sociedade e ambiente [2].

Entender verdadeiramente como a ciência é produzida e qual a sua importância faz com que as pessoas participem de forma crítica na busca pelo conhecimento. Para isso, faz-se necessário um ensino que busque a alfabetização científica dos alunos. Essa abordagem científica objetiva 
contribuir para a compreensão de conhecimentos, procedimentos e valores que permitam aos estudantes a tomar decisões e perceber as muitas utilidades da ciência e suas aplicações na melhora da qualidade de vida, além das limitações e consequências negativas de seu desenvolvimento [1].

De acordo com Scheid, Persich e Krause [3] é de suma importância que o estudante e o professor percebam que a ciência não significa somente a reunião de fatos verdadeiros em relação ao mundo, mas também a reunião de alegações e de teorias sobre esse mundo, observadas por pessoas chamadas cientistas.

A ciência não se reduz a experimentos, pelo contrário, é extremamente abrangente e complexa. O experimento científico como critério de cientificidade é ponto fundamental para o desenvolvimento das ciências exatas e biológicas ou da natureza, mais bem representadas pela física e pela biologia. Porém, esse mesmo cientificismo não é partilhado pelas disciplinas que compõem as chamadas ciências humanas e sociais (FRANCELIN, 2004, p. 27)[4].

Kosminsky e Giordané [5] afirmam que o ensino de ciências da natureza (química, física e biologia) deve proporcionar aos estudantes uma "vivência" com os elementos da cultura científica, sendo possível avaliá-los e confrontá-los com outras formas de pensar e agir, típicas de outras culturas e que também estão presentes na sala de aula.

Dessa forma, o objetivo fundamental do ensino de ciências naturais é dar condições para o aluno vivenciar o que se denomina método científico, ou seja, a partir de observações, levantar hipóteses, testá-las, refutá-las e abandoná-las quando fosse o caso, trabalhando de forma a redescobrir conhecimentos [6].

Para Silva [7] a expressão método científico representa a metodologia que define e diferencia o conhecimento da ciência de outros tipos de conhecimentos. De acordo com o mesmo autor, o conhecimento cientifico não é susceptível a natureza subjetiva. Por outro lado, existem correntes diversas da ciência que derivam, por sua vez, dos diferentes conceitos sobre realidade, percepção, teorias etc.

O presente artigo objetiva analisar as concepções acerca do método científico de calouros e formandos do curso de ciências biológicas licenciatura da Universidade Federal de Sergipe/Campus São Cristóvão (UFS). Além disso, o texto aborda uma relação entre o modo de produção da ciência e o processo de ensino e aprendizagem, já que segundo Trivelato (2002, p. 78)[8] "muitos dos estudos sobre a evolução de conceitos científicos (ou processos científicos) realizados recentemente mostraram que os alunos experimentam caminhos semelhantes aos da ciência na construção do conhecimento."

Dessa forma, reconhece-se a importância da descrição da técnica utilizada para qualquer experimento, pois, a descrição pode permitir que outros cientistas repitam o processo e possam contribuir na melhoria ou refutação de teorias. O que se busca é o entendimento de com ideias equivocadas sobre o método científico podem trazer implicações para o ensino de ciências.

\section{METODOLOGIA}

A coleta dos dados se deu através da aplicação de questionários com questões abertas elaborados pela equipe do Laboratório de Bentos Costeiros da Universidade Federal de Sergipe (LABEC).

Os questionários têm sido largamente utilizados em pesquisa na investigação de crenças e oferecem várias vantagens, são menos ameaçadores que as observações, e bastante úteis se o pesquisador tem recursos limitados e pouco tempo [9]. De acordo com Lakatos e Marconi [10], o questionário é um instrumento constituído por uma série ordenada de perguntas que devem ser respondidas por escrito, sem a presença do entrevistador, e, dentre suas vantagens, pode-se citar, por exemplo, a maior liberdade nas respostas, em razão do anonimato, e o menor risco de distorção pela não influência do pesquisador. 
Para a análise dos questionários foi utilizada a técnica de análise de conteúdo de Bardin [11]. O procedimento inicial foi a leitura geral e decodificação das respostas contidas nos questionários, com descrição detalhada das ideias, chamada de estágio descritivo ou de análise categorial. É importante destacar que as categorias nas quais os resultados foram agrupados, foram surgindo dos próprios dados e não de categorias elaboradas previamente. Após a categorização, foi realizada a fase interpretativa, com análise das manifestações dos sujeitos pesquisados para perceber que concepções de método científico apresentavam.

Os sujeitos da pesquisa foram alunos de graduação em ciências biológicas licenciatura, um grupo corresponde aos calouros e outro aos formandos. Foi aplicado um total de 88 questionários, dos quais 63 foram aplicados com iniciantes no curso, entre o primeiro e terceiro período; e 25 foram aplicados com formandos, que cursavam, no momento, o penúltimo ou último período.

Todos os participantes assinaram um Termo de Consentimento Livre e Esclarecido, atendendo dessa forma às normas do Comitê de Ética em Pesquisa (CEP) da UFS. Além disso, os graduandos foram previamente informados que os dados obtidos poderiam ser usados na pesquisa e que não há resposta correta para os questionamentos, e sim opiniões ou concepções diferentes.

Os respondentes serão identificados por códigos: calouros serão identificados pelo código $\mathrm{Cx}$ $(\mathrm{C}=$ calouro; $\mathrm{x}=$ Número do participante $)$ e os formandos por $\mathrm{Fx}(\mathrm{F}=$ formando; $\mathrm{x}=$ Número do participante).

\section{RESULTADOS E DISCUSSÃO}

$\mathrm{Na}$ análise dos dados relacionados ao conceito de método científico foram encontradas as seguintes categorias (tabela 1):

Tabela 1: Distribuição percentual dos conceitos de método científico apresentados por calouros e formandos em Ciências Biológicas Licenciatura da UFS. $N=88$.

\begin{tabular}{ccc}
\hline & \multicolumn{2}{c}{ Resultados } \\
\cline { 2 - 3 } Conceito & Calouros & Formandos \\
\hline Sistema de pesquisas padronizado & $49,2 \%$ & $44 \%$ \\
Serve para adquirir informações & $23,8 \%$ & $28 \%$ \\
Serve para provar que algo está realmente certo & $23,8 \%$ & $28 \%$ \\
Não respondeu & $3,2 \%$ & $0 \%$ \\
\hline
\end{tabular}

$\mathrm{Na}$ categoria com maior porcentual, em ambos os grupos, o método científico é visto como um conjunto de normas ou um sistema de pesquisas padronizado em que há sempre a observação de um fato para elaboração de uma teoria, como mostram algumas respostas de calouros e formandos:

C23: "É um método com etapas e procedimentos precisos e seguros para obter respostas precisas sobre determinada pesquisa."

C38: "É o rigor utilizado, os métodos que são utilizados para padronizar tudo que for de divulgação científica."

C55: "É uma forma de compreensão já estabelecida que deve ser seguidas em todas as áreas estudadas."

F1: "São organizações, ou seja, formas sistematizadas de se fazer ciência."

F4: "É um processo pelo qual se desenvolve uma determinada pesquisa. É dividido em etapas que vão desde a observação de algo, o que será estudado na pesquisa; até a formulação de uma hipótese; desenvolvimento da pesquisa até análise e discussão dos resultados."

F19: "É o método pelo qual se seguem etapas para um determinado experimento. Uma sequência de etapas que lhe permita chegar numa hipótese." 
Estas respostas apontam o método científico como a única forma de produção de ciência e comprovação de teorias. Cachapuz, Praia e Jorge [12] afirmam que essa é uma visão mecanicista do método que leva à crença muito difundida da existência de um método linear de se chegar ao conhecimento científico e acaba desfavorecendo o pluralismo metodológico.

As repostas abaixo evidenciam que o método científico é visto como uma fórmula que é prescrita por alguém e deve ser seguida rigorosamente para a produção da ciência. Tais "leis" acabam tirando criatividade e impedem que sejam feitas novas descobertas, já que quando seguimos uma receita o que se espera é que os resultados obtidos sejam os mesmos. Isso pode ser notado em algumas respostas encontradas nos questionários aplicados com os iniciantes e formandos do curso:

C25: "É a "receita de bolo" a qual deve ser seguida para se fazer ciência."

C51: "Instruções e receitas que podemos seguir para desenvolver a ciência."

Sobre as etapas desse método científico que envolve "receitas", calouros e formandos citaram algumas:

C36: "O método científico é o processo que se divide em observação, sugestão de hipótese e formulação de resultado."

F2: "É um método que consiste em algumas etapas, como a formulação de hipóteses, a experimentação."

Boa parte dos alunos afirmou que o início se dá pela observação, porém quem observa precisa ter conhecimento sobre o que está sendo observado, como ressaltam Praia, Cachapuz e Pérez [13] "Observações científicas são percepções que envolvem quase sempre alguma preparação prévia." Além disso, a observação nunca será a descrição total da realidade, pois cada indivíduo possui suas próprias ideias e pensamentos. Ademais, o observador possui um contexto histórico e social que podem influenciar na observação.

De acordo com Chalmers [14], ver a ciência, tendo como princípio a observação para a construção do conhecimento científico, é um equívoco, um engano. O autor afirma que, "de acordo com o indutivista ingênuo, a ciência começa com a observação" (Chalmers, 1999, p.24)[14].

Porém, a ideia da observação não pode ser totalmente abandonada, é necessário, sim, quebrar com a visão neutra da observação e orientá-la de forma crítica, a partir de conhecimentos prévios acerca do que é observado, como afirma Guimarães [15] deve-se levar em consideração que a observação não é feita num vazio conceitual, mas a partir de um corpo teórico que orienta a observação.

Esse método científico de neutralização da observação pode ser chamado de empirista, e possui as seguintes características:

- Não permite que o cientista seja influenciado pelas suas ideias prévias;

- Não permite nem admite a criatividade do cientista;

- Não considera o cientista parte de um contexto social, cultural e histórico;

- Não explica como é possível uma teoria ser substituída por outra ao longo da história 16].

Bastos [17] afirma que, segundo uma perspectiva empirista, os conhecimentos já estão definidos previamente e cabe ao cientista simplesmente extraí-lo da natureza. O autor completa que "este processo de aquisição de saberes em nenhum momento depende da criação ou da construção, pois nada é criado" (BASTOS, 2002, p.11)[17]. Essa ideia sustenta a concepção de imitações ingênuas da investigação científica na prática pedagógica, ou seja, que seguindo o "método científico" se obtém resultados análogos aos dos cientistas [18].

O modelo empirista de fazer ciência não é o recomendado para trabalhar com os alunos, já que a experimentação torna-se uma atividade a ser feita rigorosamente para obter resultados já esperados. Sugere-se a perspectiva não-empirista em que há a possibilidade da construção do conhecimento, com valorização das ideias e curiosidades dos cientistas.

Nesse sentido, Silveira (1992) [19] recomenda o uso de epistemologias contemporâneas que apresentem as seguintes características: - A observação e a experimentação por si só não produzem conhecimento científico; - O "método indutivo" é um mito; - Todo conhecimento, inclusive as observações, está impregnado de teorias; - O conhecimento científico é uma construção humana que tem como objetivo compreender, explicar e também agir sobre a realidade; - Na construção de novos conhecimentos participam a imaginação, intuição, a criação 
e a razão; - A aquisição de um novo conhecimento é sempre difícil e problemática. Essas epistemologias também são recomendadas como subsídio teórico para o ensino, daí que surge o construtivismo, em que o aluno é ativamente o construtor de conhecimentos [19].

Do ponto de vista pedagógico, o empirismo seria a ideia de que os alunos aprendem por absorção de informações que já estão prontas no discurso do professor, na lousa, no livro etc.; Já na visão não-empirista o conhecimento adquirido resulta de uma síntese pessoal, sendo uma reelaboração daquilo que é dito pelo professor [17].

A experimentação científica não deve funcionar no sentido da confirmação positiva das hipóteses, mas no sentido da retificação dos erros contidos nessas hipóteses. Em todo o caso, nesta perspectiva, a experimentação exige uma grande e cuidadosa preparação teórica e técnica, precedida e integrada num projeto que a orienta [13].

A segunda categoria formada com as respostas foi a que relaciona o método científico como forma de adquirir informações e produzir conhecimentos. As porcentagens encontradas entre os grupos dos calouros e formandos foram parecidas, 23,8 e 28\%, respectivamente. Algumas respostas encontradas são citadas abaixo:

C6: "Método que a ciência utiliza para adquirir informações."

C20: "Método cientifico, formas, materiais utilizados para complementar e explicar determinado estudo."

C46: "Ferramenta usada para produzir, medir ou avaliar o conhecimento."

F2: "É a maneira de produzir conhecimento científico."

Esses resultados demonstram que o uso do método científico é uma forma de produção de conhecimentos científicos. Dessa forma, tais conhecimentos são produzidos por cientistas em laboratórios, aceitos pelas comunidades científicas e impostos para a sociedade que é somente a receptora do conhecimento, no qual acredita fielmente.

Algumas respostas encontradas tanto entre os calouros, quanto entre formandos, evidenciam que os graduandos encontram-se distantes do "fazer ciência", já que o método científico é citado como uma atividade exclusiva dos cientistas renomados, como mostrado abaixo:

C1: "É a maneira como os cientistas especializados fazem as suas atividades."

C26: "São os procedimentos a ser estudado pelo cientista."

F6: "É o mecanismo com o qual o homem (cientista) utiliza para produzir a ciência, de modo que ela seja o mais possivel exata."

No âmbito do pedagógico, a ideia de método científico como produtor de conhecimentos precisa ser quebrada para que os professores saibam fazer o uso do construtivismo, incentivando os alunos na construção do próprio conhecimento. A importância do método científico para a ciência é inegável, porém é necessário contestar suas leis e paradigmas, principalmente na condução do ensino, para evitar a ideia de que a partir de métodos científicos podemos chegar a uma verdade absoluta. Marluso e Silva [18] afirmam que o método científico (empirista) é visto como alienante, conservador e veiculador de uma visão acrítica. Além disso, os autores supõem que "há diferentes caminhos para a construção do conhecimento científico e que os mesmos não são revestidos de neutralidade, estando sujeitos a intervenções, o que originou inúmeras implicações nos processos de construção do conhecimento" (MARLUSO; SILVA, 2005, p.6)[18].

A terceira categoria mostrou as seguintes porcentagens de respostas: $23,8 \%$ dos calouros afirmaram que o método científico serve para provar que algo está realmente certo e entre os formandos foi contabilizado um total de $28 \%$. Algumas destas respostas estão expressas na sequência:

C13: "São meios em que pesquisadores buscam comprovar tais fenômenos estudados."

C17: "É o método utilizado no estudo, pesquisa e experimento para alcançar resultados comprovados."

C40: "É o método que consiste em várias etapas de testes de hipóteses de um determinado questionamento para se chegar a uma resposta correta do fato."

F14: "É o método de adquirir conhecimento científico, através de comprovações de hipóteses."

F15: "É uma série de procedimentos que permitem a busca por uma verdade inerente a um processo ou fenômeno." 
Essa categoria mostra o princípio da visão da ciência como detentora do conhecimento único e verdadeiramente válido. O método científico é visto como uma técnica perfeita que só é realizada para a comprovação de teorias pré-existentes. Além disso, os resultados alcançados pelo uso do método científico são, muitas vezes, já esperados. De acordo com Marluso e Silva [18], essa ideia invalida qualquer conhecimento gerado fora da experiência da realidade crenças, valores- que são julgados como suspeitos.

Dentro dos princípios da relatividade não existe uma verdade única, existem verdades, a minha verdade, a tua verdade, a verdade do outro. E esta verdade não pode ser imposta como uma verdade única para todos, porque o pensamento é relativo, depende da minha história, da minha experiência de vida, das dificuldades que tenho elou tive, dos meus sonhos, desejos, dos meus compromissos políticos e sociais[18].

Nos resultados, não foi possível notar em nenhum momento a importância de teorias científicas que foram posteriormente refutadas, mas que merecem mérito por darem início ao estudo de determinado assunto.

Isso é visto muitas vezes no ensino de ciências, quando, por exemplo, tratamos o tema da evolução das espécies. A teoria de Lamarck é trabalhada pelos professores (e também nos livros didáticos) de forma superficial e não é mostrada a importância da sua teoria, apesar de ter sido posteriormente refutada pela teoria de Darwin. Os professores não comentam sobre a contribuição da ideia de Lamarck que deu origem às novas formas de pensar sobre as diferenças existentes entre animais da mesma espécie. Por outro lado, a teoria de Darwin é tratada como verdade absoluta que nunca será refutada. Nesse sentido o PCNEM afirma que "é possível verificar que a formulação, o sucesso ou o fracasso das diferentes teorias científicas estão associados ao seu momento histórico" (BRASIL, 2000, p. 15)[6].

Marluso e Silva [18] afirmam que existem limites, ambiguidade e inadequação no método científico, tendo em vista que não existe um único método, nem um método que assegure a veracidade de uma teoria.

Se as leis são hipóteses gerais, não há uma verdade científica e nem essa verdade está imersa, escondida, na natureza esperando por ser revelada. Não há tampouco um método científico, entendido como uma sequência de procedimentos que levariam ao conhecimento seguro, ou verdadeiro. Essas afirmações, entretanto, não diminuem a importância da experimentação na ciência [20].

De modo geral, Moreira e Ostermann (1993)[21] mostram algumas visões equivocadas do método científico que se encaixam com as respostas obtidas através dos questionários aplicados no presente trabalho. Resumidamente, são elas: -"O método científico começa na observação", segundo os autores nenhuma pesquisa científica inicia-se com a observação, antes disso são necessários conceitos, princípios e teorias que direcionam a observação; -"O método científico é lógico, rígido e ao final chega-se necessariamente ao conhecimento científico", na verdade o conhecimento científico é alcançado por meio de muitas tentativas e erros; -"O método científico é indutivo", conforme essa concepção, através de fatos poderia chegar às leis universais; - "A produção do conhecimento científico é cumulativa e linear", de acordo com os autores a ciência é predominantemente construtivista, mas não linear, pois ocorrem rupturas, crises e remodelações dessas construções, dessa forma o conhecimento científico não é definitivo.

De acordo com os PCN o objetivo fundamental do ensino de ciências é dar condições para o aluno vivenciar o método científico, trabalhando de forma a redescobrir conhecimentos. Porém, os professores não podem identificar a metodologia científica como metodologia de ensino, pois, perde-se "a oportunidade de trabalhar com os estudantes com maior amplitude e variedade, processos de investigação adequados às condições de aprendizagem e abertos a questões de natureza distinta daquelas de interesse estritamente científico" (BRASIL, 1998, p.20)[22].

É importante que o licenciando saiba as etapas do método científico, pois, talvez, esse seja o método mais utilizado nas universidades na maioria dos laboratórios. Porém, ele deve estar 
ciente da importância da investigação no processo de ensino, para que isso seja trabalhado com os seus futuros alunos, fazendo com que estes participem ativamente na construção do conhecimento por meio da problematização e não por meio da observação de experimentos que levarão sempre ao mesmo resultado. "Deve ficar claro que a experimentação na escola média tem função pedagógica, diferentemente da experiência conduzida pelo cientista" (BRASIL, 2000, p. 36) [6].

Em sala de aula, o método científico deve ser visto como uma investigação, na qual o "pesquisador" deve estudar o caso, e realizar a investigação com curiosidade e criatividade, explorando novas áreas e saberes, de modo a construir seus próprios conhecimentos acerca do caso. De acordo com os PCN o ponto de partida é a identificação de questões e problemas a serem resolvidos e o estímulo a observação, classificação e organização dos fatos e fenômenos à nossa volta segundo os aspectos físicos e funcionais relevantes [6].

\section{CONCLUSÃO}

Ao considerar as ideias que os graduandos possuem sobre método científico observou-se que as concepções de calouros e formandos em ciências biológicas licenciatura mostraram-se, muitas vezes, intimamente relacionadas a receitas prontas e a fórmulas de comprovação de teorias.

Tais ideias não correspondem à proposta do ensino de ciências através da investigação, pelo qual o educando deve ir à busca da construção dos próprios saberes, com o professor valorizando seus conhecimentos prévios, sua realidade vivenciada e os aspectos socioculturais do meio em que está inserido.

Durante o curso de graduação em ciências biológicas licenciatura os graduandos têm a oportunidade de trabalhar em diferentes laboratórios e também com pesquisa no ensino de ciências, o que pode ajudar-los a amadurecer suas concepções sobre método científico. Porém, não é o que foi observado nessa pesquisa, já que as diferenças de porcentagens entre calouros e formandos foram muito pequenas, evidenciando que as concepções dos graduandos evoluíram pouco durante o curso de formação.

Apesar da notória contribuição das oportunidades de estágio na formação dos professores de ciências e biologia, observa-se que estas não são suficientes para a formação de uma educação para ciência, ou, talvez, haja falta de interesse por falta dos licenciandos por essa temática.

Outra possível explicação para o pouco amadurecimento das concepções sobre o conhecimento científico é a abordagem científica apresentada durante todo o curso de graduação em ciências biológicas licenciatura da UFS, no qual a ciência é pouco discutida, formando, assim, professores que, possivelmente, não vão basear o ensino na forma que os conhecimentos científicos são construídos, o que implica na falta de interesse dos alunos ou em uma aprendizagem baseada em decorar os assuntos.

Para evitar essa abordagem no ensino de ciências é muito importante que a formação de professores apresente a ciência como uma forma de compreensão do mundo, em que o contexto social, econômico e político seja discutido de forma contextualizada com a ciência. Assim será possível entender a verdadeira finalidade do conhecimentos científico e compreender o papel social da ciência.

Não objetivou-se, nesse trabalho, buscar um conceito único para o método científico, tampouco diminuir sua credibilidade. O que foi proposto, aqui, foi o reconhecimento de concepções para proceder a uma análise crítica tanto do papel do método científico, quanto do nosso papel enquanto cidadãos competentes para formar pessoas capazes de compreender as atividades científicas e interferir nas ações da ciência na sociedade. 


\section{REFERÊNCIAS BIBLIOGRÁFICAS}

1. Chassot A. Alfabetização científica: uma possibilidade para a inclusão social. Revista brasileira de educação, Jan/Fev/Mar/Abr- 2003. N. 22

2. Sasseron LH, Carvalho AMP. Alfabetização científica: uma revisão bibliográfica. Investigação em Ensino de Ciências, v16(1), 2011, p. 59-77.

3. Scheid NMJ, Persich GDO, Krause JC. Concepção de natureza da ciência e a educação científica na formação inicial. In: Encontro Nacional de Pesquisas em Educação em Ciências, VII Enpec. Florianópolis, 2009.

4. Francelin MM. Ciência, senso comum e revoluções científicas: ressonâncias e paradoxos. Ciência da Informação, Brasília, set./dez. 2004. v.33, n. 3, p.26-34.

5. Kosminsky L,Giordan M. Visões de Ciência e sobre Cientista entre estudantes do Ensino Médio. Química nova na escola, Maio- 2002. n. 15

6. Brasil. Parâmetros Curriculares Nacionais para o Ensino Médio: Parte III - Ciências da Natureza, Matemática e suas Tecnologias. Ministério da Educação e Cultura. Brasília: MEC/SEF. 2000. 58 p.

7. Silva LCL. O método científico: algumas relações entre ciência, tecnologia, sociedade e ambiente. Kínesis, 2010. v.2, n.3.

8. Trivelato J. Um obstáculo à aprendizagem de conceitos em biologia: geração espontânea $\mathrm{x}$ biogênese. São Paulo: Escrituras editora, 2002. p. 77-83

9. Barcelos AMF. Metodologia de Pesquisa das Crenças sobre aprendizagem de Línguas: Estado da Arte. Rev. Brasileira de Linguística Aplicada, 2001. v.1, n .1,

10. Lakatos EM, Marconi MA. Fundamentos de metodologia Científica. 5. Ed. São Paulo: Editora Atlas, 2003.

11. Bardin L. Análise de conteúdo. Rio de Janeiro: Edições 70, 1977.

12. Cachapuz A, Praia J, Jorge M. Da educação em ciência às orientações para o ensino das ciências: um repensar epistemológico. Ciência \& Educação, 2004.v. 10, n. 3, p. 363-381,

13. Praia JF, Cachapuz AFC, Pérez DG. Problema, teoria e observação em ciência: para uma reorientação epistemológica da educação em ciência. Revista Ciência e Educação. Bauru, 2002. Vol.8, n.1.

14. Chalmers AF. O que é ciência afinal? São Paulo: Editora Brasiliense, 1999.

15. Guimarães CC. Experimentação no Ensino de Química: Caminhos e Descaminhos Rumo à Aprendizagem Significativa. Revista química nova na escola. agosto 2009. Vol. 31, N 3,

16. Trivelato SF, Silva RLF. Atividade lúdica e ensino de ciências - a biodiversidade como exemplo. São Paulo: Cengage Learning. 2011.

17. Bastos F. Construtivismo e ensino de ciências. In: NARDI, R.; Questões atuais no ensino de ciências. São Paulo: Escrituras editora, 2002. p. 9-24.

18. Marsulo MAG, Silva RMG. Os métodos científicos como possibilidade de construção de conhecimentos no ensino de ciências. Revista Electrónica de Enseñanza de lãs Ciencias. 2005. Vol. $4 \mathrm{~N}^{\mathrm{o}} 3$,

19. Silveira FL, A Filosofia da Ciência e o Ensino de Ciências. Em aberto, ano 11, n55, jul./set. 1992

20. Arruda SM, Laburú CE. Considerações sobre a função do experimento no ensino de ciências. São Paulo: Escrituras editora, 2002. p. 53-60.

21. Moreira MA, Ostermann F. Sobre o ensino do método científico. Caderno cat. Ensino de física. Porto Alegre/RS. 1993Vol. 10, n. 2. p: 108-117.

22. Brasil. Ministério da Educação. Secretaria de Educação Fundamental. Parâmetros Curriculares Nacionais: Ciências Naturais. ( $3^{\circ}$ e $4^{\circ}$ ciclos do ensino fundamental). Brasília: MEC, 1998 